\title{
INTRODUCTION OF RESIDUAL CHLORINE SENSOR USING CONSTANT VOLTAGE METHOD AND ITS MEASUREMENT PRINCIPLES
}

\author{
Juhyeong $\mathrm{KIL}^{1, *}$ \\ ${ }^{1}$ Lotus Prosuming Management ${ }^{\circledR}, 3 F, 3$ Hangeulbiseok-ro 46na-gil, Nowon-gu, Seoul, Korea
}

\begin{abstract}
In the past, we could never imagine buying drinkable water. Who would buy to drink water? But now, bottled water are sold just about anywhere in the world, but there are still many countries with water supply shortages. When drinking water is contaminated with microorganisms, it can be exposed to various diseases such as hepatitis, cholera, diarrhea, and typhoid fever. We are not only interested in drinking water, but also the water used in bathrooms, gardens, and laundry of each household. We mention "water quality" because all of these kinds of water are enough to give us a direct stimulus such as odors and greens. When we use tap water in each household, the most direct irritation is the "smell". In this case, we know that chlorine comes to mind first, and that chlorine is very useful in disinfection. Then, why are we sensitive to toxic odors in drinking water or swimming pools? The answer is simple. The effect of disinfecting with chlorine is only exerted in clear water, and we need to focus on the analysis of residual chlorine that is important for instrumental analysis. Therefore, what is introduced in this study is a "residual chlorine sensor" of a new constant voltage method that can be more accurate in measuring the amount of residual chlorine in water which is the most important factor when it comes to effectively disinfecting our drinking water.
\end{abstract}

Keywords: water quality, residual chlorine sensor, constant voltage method, water disinfection, drinking water, clean water.

\section{Introduction}

There are numerous methods of disinfection, but chlorination is the most commonly used method, while the sedimentation-filtration-disinfection progressive method is widely used for improving the quality of drinking water. This principle is simple. When chlorine comes into direct contact with microorganisms in water, it destroys the cellular structure of the microorganisms, giving the effect of disinfection. In general, residual chlorine is the effective chlorine remaining in the water as a result of chlorination such as the free residual chlorine $\left(\mathrm{Cl}_{2}, \mathrm{HOCl}, \mathrm{OCl}^{-}\right)$; free chlorine and the combined residual chlorine $\left(\mathrm{NH}_{2} \mathrm{Cl}, \mathrm{NHCl}_{2}, \mathrm{NCl}_{3}\right)$; chloramine. The amount of residual chlorine remaining 30 minutes after adding chlorine is expressed in ppm or $\mathrm{mg} / \mathrm{L}$. Free residual chlorine follows the reaction of $\mathrm{Cl}_{2}+\mathrm{H}_{2} \mathrm{O} \leftrightarrow \mathrm{HOCl}+\mathrm{H}^{+}+\mathrm{Cl}$, and when the $\mathrm{pH}$ increases, $\mathrm{HOCl}$ changes to $\mathrm{HOCl} \leftrightarrow \mathrm{H}^{+}+\mathrm{OCl}^{-}$and exists in the form of $\mathrm{HOCl}$ and $\mathrm{OCl}^{-}$in water [1,2].

Combined residual chlorine reacts when ammonia is present in water as follows: $\mathrm{NH}_{3}+$ $\mathrm{HOCl} \rightarrow \mathrm{NH}_{2} \mathrm{Cl}+\mathrm{H}_{2} \mathrm{O}\left(\mathrm{pH} 8.5\right.$ or higher), $\mathrm{NH}_{2} \mathrm{Cl}+\mathrm{HOCl} \rightarrow \mathrm{NHCl}_{2}+\mathrm{H}_{2} \mathrm{O}(\mathrm{pH} 4.5), \mathrm{NHCl}_{2}+$ $\mathrm{HOCL} \rightarrow \mathrm{NCL}_{3}+\mathrm{H}_{2} \mathrm{O}$ (pH 4.4 or less). According to the reaction of $\mathrm{NCl}_{3}+\mathrm{H}_{2} \mathrm{O}$ (pH 4.4 or less), it is classified into $\mathrm{NH}_{2} \mathrm{Cl}, \mathrm{NHCl}_{2}$ and $\mathrm{NCl}_{3}$, and these three are called combined residual chlorine [3]. These two types of residual chlorine both have oxidizing power and are chemically 
different from chlorine ions. Free residual chlorine has strong sterilization power, but most quickly disappears from the drain pipe network. The advantage here is that it prevents and disinfects the contamination of microorganisms due to a broken water pipe, and also disinfects the microorganisms that are contaminated during use [4]. And free chlorine is used in the form of chlorine $\left(\mathrm{Cl}_{2}\right)$, hypochlorous acid $(\mathrm{HOCl})$ or hypochlorite $\left(\mathrm{OCl}^{-}: \mathrm{Ca}(\mathrm{OCl})_{2}, \mathrm{NaOCl}\right)$. It acts as a potent oxidizing agent in any form, but it consumes itself rapidly as a side reaction. In many cases, there is little sterilization until more chlorine than the chlorine required is added. Hydrolysis of $\mathrm{Cl}$ chlorine reacts with water to form hypochlorous acid, hydrogen ions, and chlorine ions [5], eq (1).

$$
\mathrm{Cl}_{2}+\mathrm{H}_{2} \mathrm{O} \rightarrow \mathrm{HOCl}+\mathrm{H}^{+}+\mathrm{Cl}^{-}
$$

Hypochlorous acid is again ionized according to the $\mathrm{pH}$ of the water as follows (eq. 2):

$$
\mathrm{HOCl} \rightarrow \mathrm{H}^{+}+\mathrm{OCl}^{-}
$$

Factors that influence the sterilization effect of chlorine depend on the reaction time, temperature, $\mathrm{pH}$, and the amount of chlorine-consuming substances, and the ratio of the presence of $\mathrm{HOCl}$ or $\mathrm{OCl}^{-}$also varies (low $\mathrm{pH}$ : more formation of $\mathrm{HOCl}$, high $\mathrm{pH}$ : more $\mathrm{OCl}^{-}$) while sterilization and oxidation power is stronger in hypochlorous acid. In addition, chlorine is a very toxic suffocating gas with a pungent odor, but has a strong sterilizing power, so it is used for disinfecting tap water [6]. If free chlorine is present in wastewater, the measurement of dissolved oxygen (DO), chemical oxygen demand (COD), cyanide, etc. becomes inaccurate, so it is necessary to add sodium sulfite beforehand to reduce it.

The combined residual chlorine is present exists through the reaction of the strong binding power of chlorine with ammonia or organic nitrogen compounds in the water, so that the sterilization effect lasts a long time after disinfection without giving any bad taste or smell to water (eq. 3).

$$
\begin{gathered}
\mathrm{HOCl}+\mathrm{NH}_{3} \rightarrow \mathrm{H}_{2} \mathrm{O}+\mathrm{NH}_{2} \mathrm{Cl} \text { (monochloramine) } \mathrm{NH} \\
\mathrm{HOCl}+\mathrm{NH}_{2} \mathrm{Cl} \rightarrow \mathrm{H} 2 \mathrm{O}+\mathrm{NHCl}_{2} \text { (dichloramine) } \mathrm{NH} \\
\mathrm{HOCl}+\mathrm{NHCl}_{2} \rightarrow \mathrm{H}_{2} \mathrm{O}+\mathrm{NCl}_{3} \text { (trichloramine) } \mathrm{NHCl}
\end{gathered}
$$

Due to the chlorine treatment, enteric infectious bacteria (water-borne infectious bacteria: dysentery, cholera, typhoid fever, paratyphoid, etc.) completely disappears at $0.02 \mathrm{ppm}$ of residual chlorine after 30 minutes. Furthermore, chlorination is used to treat water, sewage, industrial water, and industrial wastewater. As an initial process in water purification treatment, the addition of chlorine for the purpose of sterilization, removal of iron or manganese, and ammonia removal is called pre-chlorine treatment [7]. Post-chlorination treatment is added just before water supply for the purpose of preserving and maintaining residual chlorine in the faucet. In sewage treatment plants, this is done before discharge.

The method of measuring residual chlorine can be largely divided into optical method, galvanic cell method, and polarography method. At this time, the galvanic measurement method which is specifically the electrochemical method, spontaneously generates a potential difference between the cathode and the anode due to electrochemical displacement in the measurement cell. The potential difference between the cathode and the anode is proportional to the chlorine concentration in the electrolyte [8]. The galvanic measuring cell is spontaneously polarized. In other words, it can be used immediately when the power is connected.

The polarographic measurement method differs from the galvanic cell method by the point of polarization. This requires an external polarization voltage to be supplied between the cathode and the anode, and after the external voltage is supplied, a current proportional to the chlorine 
concentration in the electrolyte is measured. Since a stable polarization voltage is not generated spontaneously between the cathode and the anode, time for polarization is required and it can be used thereafter. The measurement of the residual chlorine concentration is performed by connecting the residual chlorine concentration sensor to the residual chlorine meter and measuring it by galvanic or polarographic method [9]. Then, the analog signal is converted to a digital signal and amplified by receiving the electric signal from the sensor.

As explained so far, when the chlorine gas permeability is not uniform over the entire area of the diaphragm due to foreign substances attached to the diaphragm by using a gas permeable membrane through which chlorine ions permeate, the indication value is not constant and fluctuates during the measurement. There was a problem in that the measured value was not accurate due to the occurrence of hunting or swinging. According to the existing technology [1-3, 10], the residual chlorine sensor uses a diaphragm so that if a uniform tension does not work at the time of assembling in the manufacturing stage, a dent occurs in the diaphragm, which prevents chlorine ions from passing smoothly or easily tearing due to external force, causing a problem.

In addition, there is a problem in that the range for measuring the combined residual chlorine such as $\mathrm{NH}_{2} \mathrm{Cl}, \mathrm{NHCl}_{2}$, and $\mathrm{NCl}_{3}$ is limited depending on the hydrogen ion concentration $(\mathrm{pH})$. For this reason, it is possible to measure the amount of residual chlorine without being affected by the measurement range according to the hydrogen ion concentration by using an electrode instead of the conventional diaphragm. As there is no change in physical properties due to oxidation or contamination, the durability is increased and more accurate measurement is possible. This is a study on the residual chlorine sensor of the anti-voltage method that is improved to be possible. The measurement principle is as follows in the next section.

\section{Measurement Principles}

The principle of the constant voltage method introduced in this study is a new method, and the composition and principle of the electrode are different from the conventional one. The measurement principle is as follows. When working electrode WE(IN) is pt and counter electrode $\mathrm{CE}(\mathrm{EL})$ is $\mathrm{Ag} / \mathrm{AgCl}$, the reacted diffusion current can be calculated as follows (eq. 4):

\section{Diffusion current I= nAFDc/ $\alpha$ by IIKovie equation}

Here,

- $\mathrm{n}=$ quantity of electrons exchanged in a unit area;

- A = surface area of working electrode;

- $\mathrm{F}=$ Faraday constant;

- $\mathrm{D}=$ diffusion constant of the depolarizer;

- $\mathrm{c}=$ concentration of depolarizer;

- $\alpha=$ thickness of the diffusion layer between the working electrode and the solution span.

A fixed voltage of $200 \mathrm{mv}$ is configured for the reference electrode $\mathrm{R}(-)$ and the measuring electrode $\mathrm{IN}(+)$, so that the electrode voltage is a fixed value and theoretically does not fluctuate regardless of the residual chlorine concentration. At this time, if the residual chlorine concentration changes, the residual chlorine concentration can be calculated by converting the current value from the counter electrode CE (EL: anti-potential electrode).

Depending on the material to be measured, the applied fixed voltage is slightly different. For reference, the $200 \mathrm{mV}$ constant voltage is relatively effective in measuring $\mathrm{HOCL}, \mathrm{ClO}^{-}$, and $\mathrm{Cl}_{2}$ with a concentration within $20 \mathrm{ppm}$. The constant voltage residual chlorine sensor reacts to all $\mathrm{HOCL}, \mathrm{ClO}^{-}, \mathrm{Cl}_{2}$, and $\mathrm{O}_{3}$. The reason is that the electrode of the sensor is made of platinum. Platinum only differs in the reaction, and it reacts with almost all substances to generate an electric potential. Since the more $\mathrm{H}^{+}$ions there are, the more sufficient the chemical reaction 
becomes, the better the effect is to set the $\mathrm{pH}$ value to 8 or less. Also, the higher the temperature, the better the chemical reaction. Remember that the higher the concentration, the more accurate the measurement will be if you keep the $\mathrm{pH}$ and temperature values unchanged throughout the measurement process.

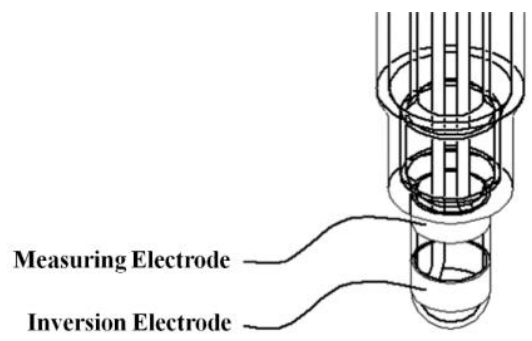

Fig. 1. Structure of the constant voltage sensor electrode

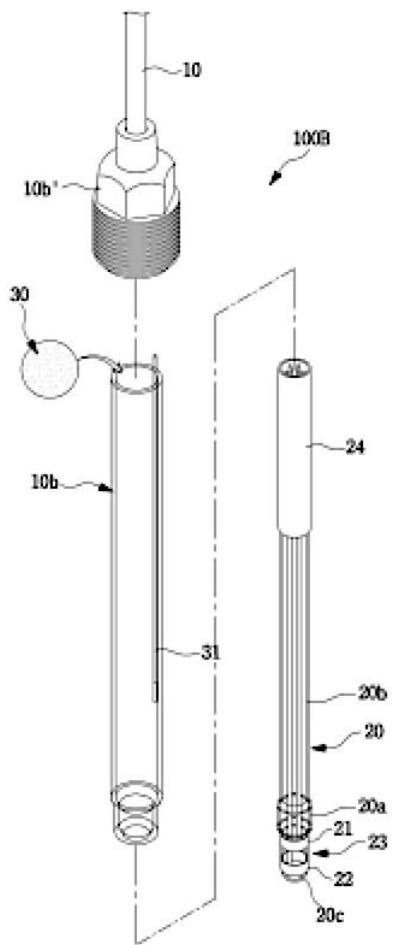

a)

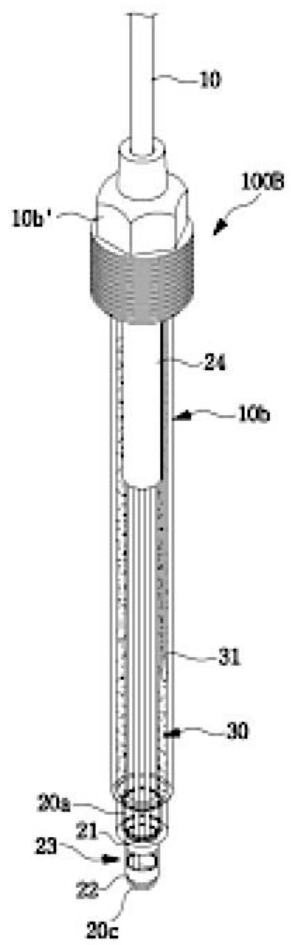

b)

Fig. 2. Constant voltage residual chlorine sensor: a) dissembled perspective view;

b) combined perspective view

\section{Sensor Configuration}

First, a sensor body (glass or plastic) on which a signal line connected to a measuring instrument is installed is formed, and on one side of the sensor body, a measuring electrode in contact with the quality of water to be measured and an inversion electrode are separated from each other to form a measuring part. On the other side of the sensor body, a reference electrode is deposited on the inner electrolyte to generate the measurement unit and the reaction potential, 
and the lower end has a sleeve junction structure in which the inner electrolyte is discharged into the water.

It has a dual structure of the body constituting the electrode and the external body (glass or plastic), and forms a three-electrode method of measuring electrode and inverted potential electrode (platinum) and reference electrode (silver/silver chloride) of the measuring unit. It is characterized that the upper electrode is configured to measure chlorine $\left(\mathrm{Cl}_{2}\right)$, hypochlorous acid $(\mathrm{HOCl})$, and hypochlorous acid ions $\left(\mathrm{OCl}^{-}\right)$, which form residual chlorine by contacting the sample to be measured.

\section{Expected Benefits}

The three-electrode method using the measuring electrode, the inversion and the reference electrode is very stable for the measured value. In addition, by using platinum as a material for the measuring electrode and the reverse-potential electrode, the measurement range is expanded by reacting to chlorine, hypochlorous acid, hypochlorite ions, and ozone, and the measurement value is more precise than the general electrochemical formula because no contamination or large physical property transformation occurs.

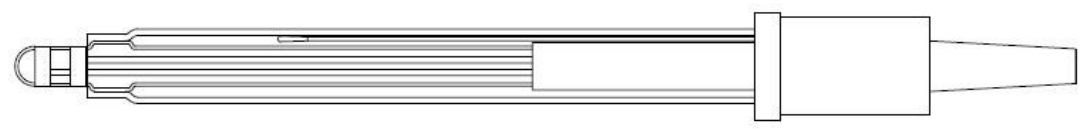

a)

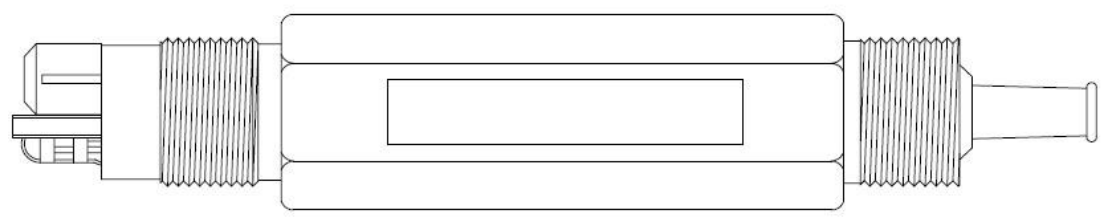

b)

Fig. 3. Constant voltage residual chlorine sensor with sleeve:

a) junction structure; b) diaphragm structure

The structure of the junction using a Teflon diaphragm rather than a sleeve junction has the advantage that the amount of internal electrolyte can be adjusted through replacement, and the internal electrolyte can be replenished if necessary, so that the sensor can be used repeatedly without replacement. In addition, there is an effect of stabilizing the measurement by adding a pigment to the internal electrolyte or blocking the influence of external interference through a shielding tube, making it easy to grasp the range of use for measurement through the naked eye.

\section{Conclusions}

Chlorine is relatively inexpensive and easy to obtain compared to the fact that most of the pathogenic microorganisms are killed by dissolving an appropriate amount of chlorine in clear water as long as the treatment process is progressed properly. As it can be seen from the fact that chlorine decreases in the process of reaction with microorganisms, if chlorine is added enough, a small amount remains even after removing all the microorganisms.

Until now, we must have learned that this is free chlorine. Free chlorine is said to be residual chlorine because it is lost to the outside or remains in the water until it is completely depleted by a subsequent reaction. If the analysis of residual chlorine in tap water can be done, it can be very simple, but it can be very important in evaluating the safety of tap water. The level of residual chlorine required depends on the type of water supply and local conditions, but in any 
case, the free residual chlorine must be maintained at an appropriate level to prevent pathogen contamination of drinking water.

From old times, chlorine has the ability to incapacitate most of the pathogenic microorganisms in an instant, so we still use chlorine $\left(\mathrm{Cl}_{2}\right)$ to treat water or industrial water used in homes and cities and to remove microorganisms from wastewater. The efficacy of chlorine depends significantly on the chlorine concentration, exposure time, and the $\mathrm{pH}$ of the water. Good management of chlorine concentration can prevent equipment contamination or reduce operating costs. However, appropriate analysis of equipment is also very important. If it's the method using the electrode method rather than the DPD method, it has had many difficulties so far.

However, if you use the constant voltage method, the story is somewhat different. As explained in the text, the constant voltage residual chlorine sensor responds to all HOCL, $\mathrm{ClO}^{-}$, $\mathrm{Cl}_{2}$, and $\mathrm{O}_{3}$. The reason is that the electrode of the sensor is made of platinum, and platinum only has a difference in reaction and reacts with almost all materials to generate a potential.

By using the advantages of the conventional galvanic cell method or the polarography method, the limitation of the measurement range according to the hydrogen ion concentration is reduced by using a three-electrode without using a gas permeable membrane, and the measurement accuracy is improved because there is no significant changes in contamination or physical properties. Through this method and principles, the history is well made in measuring residual chlorine.

\section{References}

[1] Qin, Y., Alam, A.U. et al. Integrated water quality monitoring system with $\mathrm{pH}$, free chlorine, and temperature sensors, Sensors and Actuators, B: Chemical, 2018, 255, 2.

[2] Qin, Y., Kwon, H.J. et al. Microfabricated electrochemical pH and free chlorine sensors for water quality monitoring: Recent advances and research challenges, RSC Advances, 2015, $5,85,8$.

[3] Zhang, T., Pramanik, G. et al. Toward Quantitative Bio-sensing with Nitrogen-Vacancy Center in Diamond, ACS Sensors, 2021, 5.

[4] Downs, A.M., Gerson, J. et al. Nanoporous Gold for the Miniaturization of In Vivo Electrochemical Aptamer-Based Sensors, ACS Sensors, 2021, 5.

[5] Moore, C., Borum, R.M. et al. Activatable Carbocyanine Dimers for Photoacoustic and Fluorescent Detection of Protease Activity. ACS sensors, 2021, 5.

[6] Feng, P.I., Xia, Z. et al., Enhancing the Performance of Fabric-Based Triboelectric Nanogenerators by Structural and Chemical Modification, ACS Applied Materials and Interfaces, 2021, 13, 14, 4.

[7] Storey, M.V. Bram van der Gaag et al. Advances in on-line drinking water quality monitoring and early warning systems, Water Research, 2011, 45, 2.

[8] Banna, M.H., Imran, S. et al. Online drinking water quality monitoring: Review on available and emerging technologies, Critical Reviews in Environmental Science and Technology, 2014, 44, 12, 6.

[9] Feng, Y., Smith, D.W. et al. Photolysis of aqueous free chlorine species ( $\mathrm{HOCl}$ and $\mathrm{OCl}$-) with $254 \mathrm{~nm}$ ultraviolet light, Journal of Environmental Engineering and Science, 2007, $6,3$.

[10] Badihi-Mossberg, M. Virginia Buchner et al. Electrochemical biosensors for pollutants in the environment, Electroanalysis, 2007, 19, 19-20, 10.

Received: March 18, 2021

Accepted: May 02, 2021 